\title{
DROPANDO SOBRE AS PRANCHAS: OS IMPACTOS DAS TRANSFORMAÇÕES CONCEITUAIS DAS PRÁTICAS DO SURFE E DO SKATE REFLETIDOS NO ANÚNCIO DO COMITÊ OLÍMPICO INTERNACIONAL
}

\author{
Dropping onto the boards: The impacts of conceptual changes in surfing \\ and skateboarding practices reflected in the announcement of the \\ International Olympic Committee
}

Monique de Souza Sant'Anna Fogliatto'
José Carlos Marques

\begin{abstract}
RESUMO
Caracterizadas como atividades de lazer pautadas pela resistência e subversão da mentalidade conservadora vigente entre as décadas de 1950-80, as práticas do surfe e skate se transformaram em modalidades olímpicas estreantes na edição de 2020, com sede em Tóquio, Japão. Para analisar o evento histórico do anúncio da inclusão do skate e surfe como modalidades olímpicas, utilizamos como objeto as publicações de dois conglomerados de mídia: as páginas Globo Esporte e Folha de São Paulo, sustentado na proposta de que o jornal, enquanto força comunicativa, funciona como objeto para reconstrução posterior de eventos históricos. Para construir o plano de fundo da discussão, utilizamos os conceitos de mentalidade, identidade e imaginário, sustentados por Sandra Pesavento e Branislaw Baczo, articuladas com as reflexões historiográficas de Eric Hobsbawm. No âmbito da Sociologia do Esporte, as discussões conceituais se desenvolveram com base em uma variedade de autores, tendo como principais Norbert Elias e Eric Dunning, Roger Caillois, Johan Huizinga, Manoel Tubino, Valdir Barbanti e Roland Barthes. Através da análise das matérias, foi possível notar a construção de um ambiente extremamente favorável, apoiados principalmente na justificativa mercadológica dos Jogos ao usarem como público alvo a juventude.
\end{abstract}

Palavras-chave: Surfe e skate; Modalidades Olímpicas; Cobertura Jornalística

\begin{abstract}
1 Graduada em Comunicação Social - Habilitação em Jornalismo pela Universidade Federal de Mato Grosso. Atualmente é mestranda do Programa de Pós-Graduação em Comunicação pela Universidade Estadual Paulista (Unesp) em Bauru. E-mail: moniquefogliatto@gmail.com. ORCID: https://orcid.org/0000-0003-2402-4309.

2 Professor Associado da Universidade Estadual Paulista (Unesp/Bauru), instituição onde atua também como docente do Programa de Pós-graduação em Comunicação e do Departamento de Ciências Humanas da Faculdade de Arquitetura, Artes e Comunicação. É Livre-Docente em Comunicação e Esporte pela Unesp, Doutor em Ciências da Comunicação pela Escola de Comunicações e Artes da Universidade de São Paulo e Mestre em Comunicação e Semiótica pela Pontifícia Universidade Católica de São Paulo. E-mail: zeca.marques@faac.unesp.br.
\end{abstract}


Characterized as leisure activities guided by the resistance and subversion of the conservative mentality prevailing between the $1950 \mathrm{~s}$ and $80 \mathrm{~s}$, as surfing and skateboarding practices became debut Olympic modalities in the 2020 edition, based in Tokyo, Japan. To analyze the historical event of the announcement of the inclusion of skateboard and as Olympics modalities, we used as object the publications of two media groups: the pages Globo Esporte and Folha de São Paulo, supported by the proposal that the newspaper, as a communication force, it works as object for later reconstruction of historical events. To build the background of the discussion, we used the concepts of mentality, identity and imagination, supported by Sandra Pesavento and Branislaw Baczo, articulated with the historiographic reflections of Eric Hobsbawm. Within the scope of Sociology of Sport, the conceptual discussions were developed based on a variety of authors, with Norbert Elias and Eric Dunning, Roger Caillois, Johan Huizinga, Manoel Tubino, Valdir Barbanti and Roland Barthes as main authors. Through the analysis of the articles, it was possible to notice the construction of an extremely favorable environment, supported mainly by the market justification of the Games by using the youth as a target audience.

Keywords: Surf and Skate; Olympic Sports; News Coverage

\section{Introdução}

Apresentamos este artigo como uma forma de propor reflexões e levantar questionamentos a respeito das transformações conceituais das práticas do surfe e do skate enquanto atividades que têm como premissa a sociabilidade e a resistência à mentalidade socialmente partilhada sobre determinadas identidades, elementos que participaram do contexto de sua concepção e popularização e que se fazem presentes até a contemporaneidade.

Para Sandra Jatahy Pesavento (2012, p.51), a mentalidade “(...) se ligava à permanência e a uma comunidade de sentido, partilhada por todos, a atravessar o social de ponta a ponta. (...) o imaginário se ofereceu como a categoria preferencial para exprimir a capacidade dos homens para representar o mundo". Longe de tentar reconstruir a história das modalidades, algo inevitavelmente presente em nossas reflexões, nos interessa aqui buscar reconstruir como o anúncio, da inclusão delas enquanto modalidades olímpicas, é resultado de um processo de mudança de mentalidade instituída durante várias décadas.

O objeto deste artigo deve-se a um importante evento: nascidas enquanto práticas tipicamente juvenis e consideradas desviantes na mentalidade partilhada durante décadas, elas passaram a ser consideradas eventos típicos de importância social e de relevância jornalística devido, principalmente, à premiação, em níveis internacionais, de atletas brasileiros. Tal evento acarretou o aumento de popularidade do skate e do surfe, abrindo espaço na relevância midiática conferida na editoria de esportes dos mais variados meios de comunicação. Surfistas e skatistas passaram a ser conhecidos e acompanhados por uma multidão que não estava mais apenas restrita ao círculo social destes, mas que, agora, podia conhecer e se familiarizar com nomes, conceitos e regras, enfim, elementos culturais que antes compunham apenas a realidade dos seus praticantes e que agora se popularizaram através dos meios de comunicação. 


\section{O surfe e o skate: Caminhos tortuosos}

Muito mais do que o equilíbrio de um corpo sobre pranchas, o skate e o surfe marcaram a mentalidade coletiva entre as décadas de 1950 e 1980, momento este em que as duas práticas passaram a ganhar espaço enquanto modalidades esportivas através da esportivização. Falar de ambas é impossível se pretendermos dissociá-las do contexto em que elas têm suas raízes fundadas. (DUNNING; ELIAS, 1992)

Sabe-se que as histórias destas atividades estão entrecruzadas. Começaremos, portanto, com a mais antiga delas. Muito mais do que representar uma prática, o surfe traz consigo algumas importantes peculiaridades que nos ajudarão a compreender sua importância simbólica, tanto no cenário mundial como em terras brasileiras. Tendo sua origem disputada entre os povos peruanos e polinésios, o ato de se equilibrar sobre um pedaço aplainado de madeira marcava um elemento que simbolizava o descarregar de energias negativas. Este ato, carregando sentidos e simbolismos, se tornou a marca histórica da prática. Assim, mais do que puramente o ato, o que nos importa dizer é que a importância simbólica o perpassa e, neste caso, o espaço assume uma nova configuração que extrapola aquela do acontecimento restrito a um intervalo de tempo, se instalando de maneiras múltiplas no imaginário social, em vezes muito distintas da concepção em que surgiu. (BERGER E LUCKMANN, 2014). Para Bronislaw Baczko (1984)

[...] é por meio do imaginário que se podem atingir as aspirações, os medos e as esperanças de um povo. É nele que as sociedades esboçam suas identidades e objetivos, detectam seus inimigos e, ainda, organizam seu passado, presente e futuro. O imaginário social se expressa por ideologias e utopias, e também por símbolos, alegorias, rituais e mitos. Tais elementos plasmam visões de mundo e modelam condutas e estilos de vida, em movimentos contínuos ou descontínuos de preservação da ordem vigente ou de introdução de mudanças. (BACZKO, 1984, p.54)

Quando nos indagamos a respeito da prática do surfe, outros elementos simbólicos certamente virão à nossa mente: a relação de harmonia com o espaço de sua realização, o estilo de vida marcado pelo sossego e seus praticantes identificados por seus corpos dourados, estilos de vestimentas e cortes de cabelo característicos são alguns deles, o que conferem a seus praticantes uma identidade um tanto quanto singular, se configurando como um produto do meio social. Em um mundo marcado pela multiplicidade de indivíduos cujas identidades são igualmente múltiplas, a identidade construída "por", "sobre" e "para" os indivíduos ocupa espaço central para compreender a importância desta atitude no processo de identificação dos membros de uma dada coletividade. Para Sandra Jatahy Pesavento (2012)

(...) a identidade é uma construção simbólica de sentido, que organiza um sistema compreensivo a partir da ideia de pertencimento. A identidade é uma construção imaginária que produz a coesão social, permitindo a identificação da parte com o todo, do indivíduo frente a uma coletividade, estabelece a diferença. A identidade é relacional, pois ela se constitui a partir da identificação de uma alteridade. Frente ao eu ou ao nós do pertencimento se coloca a estrangeiridade do outro. (PESAVENTO, 2012, p.23) 
Seguindo o mesmo percurso que a atividade que lhe deu origem, o skate inaugurou uma nova forma de se relacionar com os espaços urbanos, sendo popularizados nestes ambientes a partir da década de 1960. Deslizando suas pranchas, agora equilibradas sob quatro rodinhas, os skatistas reforçaram a ideia de lugarização dos espaços ao proporem usos que originalmente não estavam previstos por aqueles responsáveis pela urbanização das cidades. Este evento está ligado, principalmente, a um evento de fuga da regularidade das ondas californianas, que resultou na migração dos surfistas para piscinas de bordas arredondadas, e, posteriormente, para outros espaços compartilhados, o que resultou em estigmas postos sobre estes indivíduos. (BRANDÃO, 2014). Pouco a pouco, o skate foi se afastando do surfe, produzindo identidade própria, que, para Brandão (2014, p.26) inaugurou “(...) um novo modus vivendi (...) outras e renovadas formas de pensar, sentir e representar o meio social".

As pranchas, antes mais compridas, foram encurtadas e equilibradas em quatro rodas, passando a serem utilizadas sobre as calçadas e o asfalto, ganhando os espaços públicos que outrora tinham outra finalidade. De uma hora para outra, piscinas de bordas arredondadas de casas abandonadas, corrimões, bancos de praças e ladeiras, além de diversos outros equipamentos urbanos, se tornaram suporte por onde as rodinhas se apoiavam para realização de manobras. $\mathrm{O}$ uso imprevisto desses espaços tipicamente concebidos visando à ordem social coletivizada trouxe à tona aspectos relevantes a serem considerados. $\mathrm{O}$ fato é que o meio urbano, tal como qualquer outro produto social, é concebido como um palco de possibilidade de ações dos mais variados atores sociais que ajudam a compor e a construir sentidos e significações nos ambientes partilhados. Muito mais do que uma planta ou o resultado de um planejamento objetivo, o espaço urbano é produto da sociabilidade, sendo este resultado das múltiplas apropriações assumidas pelos sujeitos, que se tornam "agentes transformadores do espaço da cidade", fazendo-a ganhar múltiplas dimensões simbólicas que se transformaram em resultado da capacidade comunicativa entre estes (DIAS, 2008; JACOBS, 2014; SANTOS, 2006). Ao nos questionarmos a respeito do uso desse espaço, vemos que ele se tornou um produto: longe de parecer um mero espaço de trânsito, estes ambientes se tornam comunicativos. Mas, apesar de parecer que este tem um sentido único, imutável, o que se pode perceber é que os indivíduos, cada qual exercendo sua subjetividade e trazendo à tona suas atribuições de sentidos norteadas por suas mediações, são responsáveis por fazer dos espaços ambientes vivos, dinâmicos e mutáveis (SERPA, 2018; CARLOS; SOUZA; SPOSITO, 2019).

Trazer à tona discussões sobre skate e surfe é acarretar inerentemente a contraposição dos conceitos de espaço e lugar. O primeiro, apresentado simplesmente como um elemento sólido e imutável, não confere a importância detida pela territorialidade ocupada por múltiplas coletividades. É nesta perspectiva que defendemos a importância do lugar enquanto elemento importante para compreender como as duas práticas, aqui tomadas como objeto de pesquisa, se tornaram objeto de discussão e estereotipação. Este segundo conceito confere emancipação aos sujeitos, que passam a ser entendidos como ativos no processo de produção de sentido no meio social. No conceito de lugar, as múltiplas significações conferidas ao espaço se tornam igualmente válidas e coexistem entre si de forma a tornar este espaço um ambiente que seja palco para expressão das mais variadas subjetividades (MAGNANI, 1993; CERTEAU, 1996; TUAN. 1983). Neste contexto, a juventude, parcela que caracteriza a maioria de praticantes do skate e surfe, emerge como importante elemento para construção simbólica dos espaços, se tornando alvo de construções discursivas que em nada lhes são benéficas. Sustentados pelas reflexões de Dayrell (2003), Couto et.al (2019) afirmam que 
(...) o jovem (...) na condição de sujeito social, constrói o seu determinado (e próprio) modo de ser (e de estar) no mundo, pertencendo a determinadas condições sociais, (...) aos aspectos socioeconômicos, culturais (...), de gênero, a regiões geográficas, fatores tais que o(a) particulariza. (COUTO et al, 2019, p.39)

Surfar nos oceanos ou até mesmo sobre superfícies asfálticas trazia consigo um elemento de diferenciação social: exigia tempo, dedicação e um estilo de vida que em nada se assemelhavam àquela vivida pelas parcelas sociais mais abastadas, que tinham um restrito tempo destinado ao ócio e um acesso por vezes restrito aos locais utilizados para as práticas. Além disso, é preciso entender que, para além da simples realização do ato, as atividades exigiam de seus praticantes um estilo de vida, vestimentas, linguagens e equipamentos que se distanciavam do viés popular.

Denominado como A Era dos Extremos (HOBSBAWM, 1995), o século XX, mais precisamente as décadas de 1960-70, ficou marcado por importantes eventos históricos que inauguraram novas configurações sociais, culturais, políticas e econômicas que, no caso brasileiro, se configuraram como um tanto quanto dualistas. De um lado, o ano de 1964 trazia à tona o período conhecido como "Anos de Chumbo", marcado pelo autoritarismo e restrição à liberdade de expressão social e de imprensa. De outro, víamos refletidos os impactos das revoluções sociais, culturais, políticas e econômicas vindas do exterior, que trouxeram à tona novas configurações conceituais de família, comportamento e sociedade que colocavam o "nós" sobreposto ao "eu", mas, sobretudo, ressaltava o caráter ativo dos mais diversos sujeitos que partilhavam um mesmo meio social (HOBSBAWM, 1995).

É nesse cenário que a juventude brasileira tentava, a custo da repressão e do cerceamento de liberdades, instituir uma nova mentalidade nos mais diversos setores sociais, ainda que relativamente sem sucesso. Conforme analisa Eric Hobsbawm, neste período a juventude foi colocada em destaque devido, principalmente, a três elementos básicos: a visão da juventude como último grau de desenvolvimento humano; o fato de tornar a juventude um público de consumo extremamente viável e; a possibilidade de internacionalização propiciada pelas práticas juvenis. Foi nesse cenário que "A cultura jovem tomou-se a matriz da revolução cultural no sentido mais amplo de uma revolução nos modos e costumes, nos meios de gozar o lazer e nas artes comerciais, que formavam cada vez mais a atmosfera respirada por homens e mulheres urbanos." (HOBSBAWM, 1995, p.323).

\section{A metamorfose das práticas}

\section{A transformação do esporte em modalidade olímpica}

Muito mais do que uma simples brincadeira, surfe e skate, apesar das transformações conceituais, ainda carregam aspectos ligados às práticas de jogo. Para Roger Caillois, mais do 
que isso, o jogo traz uma importante lição para a vida corrente.

O jogo não nos prepara para nenhuma atividade definida; de uma maneira geral, é introduzido na vida, acrescentando a ela toda capacidade de se livrar de obstáculos ou de fazer oposição às dificuldades. (...) Além disso, é necessário aceitar de antemão o possível fracasso, má sorte ou fatalidade. (CAILLOIS, 1990, p.18)

Mas, afinal, por que esta categoria ainda se encontra intimamente relacionada às atividades sobre pranchas? Para ser considerada como jogo, determinada atividade tem que possuir algumas características básicas. Johan Huizinga (1971), o primeiro a teorizar o conceito, nos expõe que este, em sua gênese, é uma atividade voluntária, desinteressada, temporária e com finalidade autônoma, não se caracterizando enquanto vida real, tendo suas regras e ordens próprias.

Retomando as reflexões de Huizinga e trazendo ao conceito importantes características definidoras, Roger Caillois (1990) atribui ao jogo elementos de classificação. Assim, para ele, o jogo além de ser uma atividade livre, delimitada, incerta e improdutiva, regulamentada e fictícia, ainda traz consigo elementos que podem aparecer em conjunto ou isolados, a depender de sua natureza. São eles: agôn, alea, mimicry e ilinx.

O que nos interessa, dentre estas dimensões do jogo é trazer à tona que o surfe e o skate trazem como elemento principal de sua execução o ilinx, ou a busca da vertigem. É ele que traz às duas atividades a íntima relação com o risco iminente e, consequentemente, o faz serem conhecidas e praticadas pelas sensações extremas que causam aos seus adeptos. Neste caso, mais do que a superação de seus oponentes, mesmo que ainda na classificação de jogo, é necessário que os praticantes superem obstáculos que, antes de tudo, se encontram no espaço, no lugar que ocupam para realização da prática. (DUNNING; ELIAS, 1992).

As duas modalidades aqui estudadas trazem à tona a discussão a respeito da busca pela vertigem, na medida em que estabelecem a relação entre o risco controlado e as sensações desencadeadas no corpo. Para David Le Breton, nas palavras de Leonardo Brandão (2014, p.86-87) esta relação é representada por uma espécie de rito ordálico contemporâneo, ou uma “(...) espécie de enfrentamento metafórico com a morte, na qual seus praticantes visariam uma transcendência pessoal, um "viver mais"”. O que importa é que esta busca pela vertigem, muito mais do que uma interpretação literal do conceito, está intimamente relacionada ao caráter subversivo e desviante que ambas as atividades tomaram entre as décadas de 1960 e 1980. Para Roger Caillois, muito mais do que uma vertigem de desencadeamento físico, "Existe, em paralelo, uma vertigem de ordem moral, que se apodera subitamente do indivíduo. Essa vertigem associa-se habitualmente ao gosto, normalmente reprimido, pela desordem e pela destruição" (CAILLOIS, 1990, p.44-45).

A popularização das práticas fez com que aumentasse o interesse de seus praticantes pela profissionalização delas, em uma tentativa de fazer com que aquilo que era visto como hobby, mas também um estilo de ser, estar e pensar, se tornasse uma ferramenta de reconhecimento, passando a ser um modo de "ganhar a vida". É nesse cenário conturbado, entre reconhecimentos e marginalizações, que o surfe e o skate ganharam ares de esporte. Mas, afinal, o que vem a ser esporte e, mais do que isso, como estes se tornaram olímpicos? A resposta ao primeiro questionamento foi objeto de reflexão de diversos autores que ajudaram a formar uma área 
singular, a sociologia do esporte.

Nascida na contemporaneidade como fruto da mentalidade industrial, o esporte deixou um pouco de lado o elemento da exaltação e do ritual, tal como foi concebido ainda na Antiguidade. Para nos auxiliar a entender sua complexidade, primeiramente nos apoiaremos na definição apresentada por Valdir Barbanti (2006), que avalia que "Esporte é uma atividade competitiva institucionalizada que envolve esforço físico vigoroso ou o uso de habilidades motoras relativamente complexas, por indivíduos, cuja participação é motivada por uma combinação de fatores intrínsecos e extrínsecos" (BARBANTI, 2006, p.57). Porém, tal como sabemos, o conceito foi se desdobrando, o que fizeram surgir conceituações que subdividiram esporte em algumas importantes categorias. Isto serviu para entender que, muito mais do que uma simples denominação, a mentalidade socializada influenciava bastante na imagem que se tinha desta "esportivização". Assim, passou-se a classificar o esporte enquanto participação, educação ou performance ${ }^{3}$.

O que nos interessa aqui é nos debruçar na categoria de esporte-performance, responsável pela popularização e consequente mercantilização do surfe e do skate não só em solo nacional, mas internacional. Caracterizado pela subserviência a regras e particularidades, esta categoria de esporte traz consigo a mentalidade mercantil posta sobre o conceito de esporte no período pós-Revolução Industrial. Colocando como prioridade o desempenho dos atletas, mas visando a conquista que mais do que individual serve para gerar o sentimento de orgulho e identificação nacional, nesta categoria o esporte é elevado ao quadrado, tal como nos apresenta Umberto Eco (2016), fazendo com que a prática se configure como espetáculo, estando sua conversão intimamente relacionada com a importância dos meios de comunicação na projeção de suas imagens.

Ao ganhar o espaço midiático, as práticas esportivas assumem uma maior importância no imaginário social, fazendo com que seus praticantes, para além de serem vistos como atletas, se tornem espelhos a serem seguidos, ídolos a serem contemplados ou até mesmo mitos, que perpassarão as territorialidades e temporalidades em que estão inseridos. Diante disso, o que significa para os esportes cruzarem a fronteira e se tornarem olímpicos? Reunindo rituais, representações e simbolismos que perpassam o discurso produzido sobre o evento, os Jogos Olímpicos já não são mais conhecidos tal como propostos em sua concepção original. Vimos, pouco a pouco, a exaltação do ritual se converter em exaltação do mercantil, tornando os esportes cada vez mais objetos de consumo. Apesar de ainda propor a exaltação dos indivíduos por suas qualidades individuais, ainda que estejam em disputas coletivas, este evento se revestiu de um caráter midiático que em nada agradou os praticantes do surfe e skate, tomados como objeto desta discussão.

Podemos dizer que, para se tornar olímpico, o esporte tem que se "olimpicizar". Muito mais do que garantir a esportivização e a institucionalização, o que caracteriza o esporte olímpico é a exaltação excessiva da competição em determinados esportes, fazendo deste um propósito maior para espetacularização das atividades. O fato é que, segundo Manoel Tubino (1994, p.34), "A busca permanente do espetáculo esportivo e o abandono gradual das competições que não despertassem o interesse do público foram as principais causas da reacomodação dos

3 As conceituações não desdobradas neste artigo estão explicitadas na obra “O que é esporte?” de Manoel Tubino (1994) 
esportes olímpicos".

Porém, diferente de outras modalidades, o que se observou no caso do surfe e do skate é que seus praticantes não ficaram muito satisfeitos com o anúncio das práticas como modalidades olímpicas. Carregadas de simbolismos de grupos singulares, ambas as práticas se caracterizam ainda hoje como elementos de resistência, tendo a subversão pacífica a normas instituídas dentre a sua configuração. Além disso, tornarem-se olímpicas, primeiramente, trouxe à tona as questões relacionais com o espaço: no caso do surfe, primeiramente foi proposto que a disputa seria feita em piscinas de ondas artificiais, que trariam "igualdade" à competição, enquanto se levantou a hipótese da construção de espaços de simulacro da rua, no caso do skate street.

Ambas as saídas foram vistas com maus olhos por seus praticantes. Muito mais do que uma simples simulação que retiraria o caráter radical do ato de praticar skate e surfe, pensar a disputa das modalidades esportivas simulando-se o uso dos espaços era uma afronta a uma história que se consolidava na história nacional desde meados dos Anos de Chumbo. Além disso, é preciso dizer que, na contemporaneidade, o espaço midiático ocupado por ambas as práticas não tem como foco principal o fato de a competição em dimensões olímpicas se tornarem mais importantes que os campeonatos mundiais disputados em todas as categorias destas duas modalidades esportivas. Organizados na forma de circuitos mundiais, envolvendo patrocínios significativos e premiações ainda mais atrativas, as práticas, no caráter profissional de skate e surfe, já são consolidadas, fazendo parte do calendário esportivo de atletas e admiradores. O que se poderia aqui afirmar é que, tornar-se olímpico, talvez serviria como uma mola propulsora para o alcance de novos públicos e de possíveis novos praticantes, bem como um possível incremento nos patrocinadores para futuros eventos esportivos de ambas.

Para além dos aspectos positivos da olimpização, representados pelo maior espaço midiático e a possibilidade de conquistar um público cada vez maior, é preciso dizer que esta transformação traz à tona questionamentos importantes. O que o tornar-se olímpico significa? Apesar de se tornar um evento primordialmente comercial, as Olimpíadas ainda carregam consigo elementos rituais e símbolos que a tornam elemento singular. Assim sendo, ao se tornarem olímpicos, o skate e o surfe se colocam no interior deste universo, o que, em parte, limitam as práticas a certos padrões. Cabe a nós questionar a respeito da relação estabelecida entre o "tornar-se olímpico" e a manutenção dos aspectos identitários carregados pelas duas práticas. Como esta relação irá se constituir? Os elementos característicos serão postos de lado e seus praticantes irão submeter a imposições que os colocarão em "padrões olímpicos"? Como ainda não temos certeza desta representação discursiva, o que nos resta é levantar questionamentos.

\section{Quando o lazer se tornou olímpico: O anúncio de inclusão das atividades sobre pranchas}

Para nos auxiliar no desenvolvimento deste artigo, estabelecemos como objeto de pesquisa o anúncio do skate e do surfe enquanto uma das cinco modalidades olímpicas inéditas da edição de 2020, com sede em Tóquio, no Japão. Para tanto, elegemos dois portais de notícias online para avaliar o tratamento deste evento: o portal Globo Esporte, do Grupo Globo de Comunicações, escolhido por fazer parte do grupo editorial responsável pela transmissão 
oficial deste evento e a versão online da Folha de São Paulo, justificada por se configurar entre os maiores e mais consumidos veículos de comunicação do país ${ }^{4}$. Para melhor desenvolver a pesquisa e evitar um corpus demasiadamente extenso, vamos nos ater às publicações realizadas no período de uma semana após a divulgação do ineditismo das cinco modalidades olímpicas: skate, surfe, caratê, escalada e beisebol/softbol. A exceção desta pesquisa está na análise de uma reportagem publicada em 1o de junho de 2016 pelo portal Globo Esporte, que trata da recomendação do Comitê Olímpico Internacional (COI) para inclusão das modalidades na edição de 2020, que tem como sede a cidade de Tóquio, no Japão, a fim de que possamos analisar o cenário construído a priori da indicação da inserção de novas modalidades no quadro olímpico.

A escolha dos objetos está ancorada no surgimento dos veículos midiáticos que lhes deram origem. Os grupos Globo e Folha de São Paulo representam os principais conglomerados de mídia do país. O primeiro deles foi criado por membros da família Marinho em 25 de julho de 1925 e por Luís Frias, em 1921, respectivamente. A trajetória de ambos e os momentos por eles retratados através das páginas dos jornais no decorrer das décadas nos permite afirmar a força noticiosa de ambas enquanto formadoras de opinião e responsáveis pela propagação de informações relevantes.

O que nos importa aqui apresentar é a relevância da informação por eles transmitida e, para além disso, confirmar a continuidade da credibilidade tida por ambos os aglomerados de mídia mesmo após a chegada das Novas Tecnologias da Informação e Comunicação. Para Marialva Barbosa, o jornal, assim como os suportes que possibilitaram sua difusão pelos demais aparatos tecnológicos

Apreende o social em sua dimensão total (incluindo a cultura, a dimensão econômica, política, mas também o simbólico ou o imaginário) e, ao mesmo tempo, se considera que a narrativa histórica é, sobretudo, um artefato literário, no qual está incluída a dimensão fictícia dos relatos. (BARBOSA, 2008, p.1)

Para além de todas as discussões aqui empreendidas, o que nos vale ressaltar é a importância da narrativa jornalística enquanto documento a ser utilizado a posteriori para reconstituição de determinado momento histórico, servindo como "[...] agente histórico" que intervém nos processos e episódios [...]" (MORGADO, 2011 apud MOREL, 2008, p.8-9). A relevância desta fonte só passou a ser considerada por membros da Escola dos Annales. Neste momento histórico, o campo historiográfico pôde ter suas fontes ampliadas e, através delas, pode-se entender o passado através das narrativas construídas sobre grupos sociais. Para Lucien Febvre

A história faz-se com documentos escritos, sem dúvida. Quando eles existem. Mas ela pode fazer-se, ela deve fazer-se sem documentos escritos, se os não houver. Com tudo o que o engenho do historiador pode permitirlhe utilizar para fabricar o seu mel, à falta de flores habituais. Portanto, com palavras. Com signos. Com paisagens e telhas. Com formas de cultivo

4 Dados colhidos de pesquisa realizada pela ONG Intervozes - Coletivo Brasil de Comunicação Social em 2017. Disponível em https://intervozes.org.br/apoio-institucional/ acessado em 25 de março de 2020 
e ervas daninhas. Com eclipses da lua e cangas de bois. Com exames de pedras por geólogos e análises de espadas de metal por químicos. Numa palavra, com tudo aquilo que pertence ao homem, depende do homem, serve o homem, exprime o homem, significa a presença, a atividade, os gostos e as maneiras de ser do homem... (FEBVRE, 1985, p.249).

\section{Imagem 01: Portal Globo Esporte}

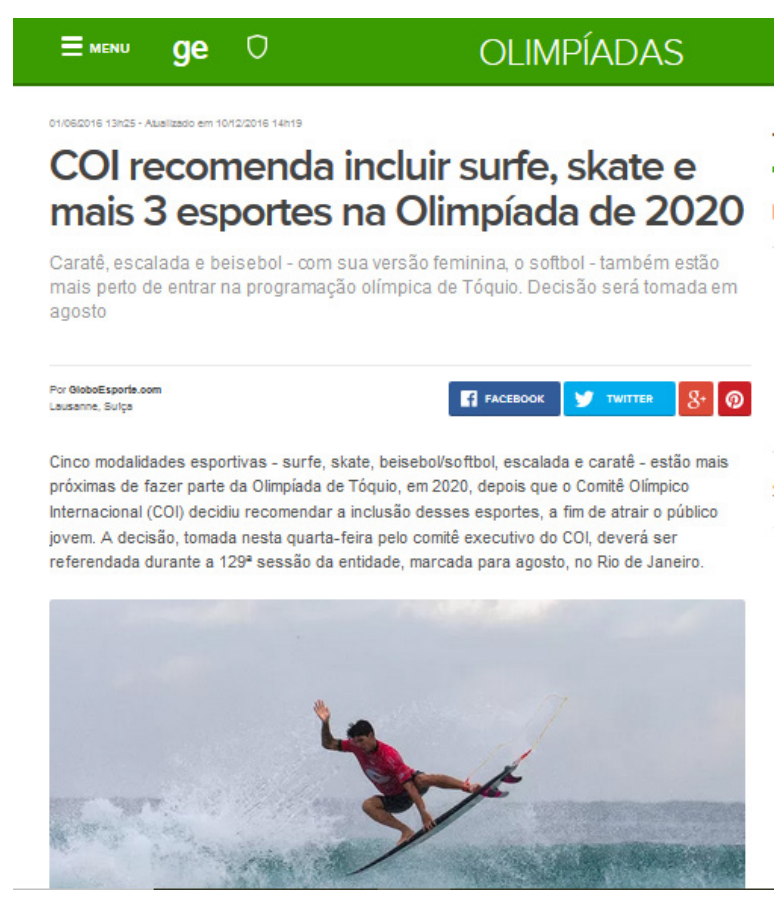

A primeira matéria, considerada a notícia inaugural da proposta de inserção das novas modalidades olímpicas, cenário o qual estão inseridos skate e surfe, foi publicada em 10 de junho de 2016. Naquele cenário construído, permeado de uma certa incerteza quanto à inserção do skate e do surfe no rol de modalidades olímpicas, o jornalista opta por construir um cenário que contextualize o que parece, àquele momento, ser um fato a ser consolidado. Segundo ele "A mudança faz parte do pacote de reformas iniciadas pelo presidente do COI, Thomas Bach, em dezembro de 2014".

Mas, afinal, em que argumentos estariam sustentadas as inclusões de modalidades olímpicas como o surfe e skate, aqui tomadas como objeto de estudo? Podemos extrair da matéria dois pilares que sustentam tal decisão: a possibilidade de atrair um público jovem, que serviria de espectadores potenciais às tais modalidades e o reforço da proposta de tradição, 
já que, segundo as palavras do jornalista, "os anfitriões dos Jogos terão a chance de trazer ao ambiente olímpico, esportes que sejam mais populares em seus países, com intenção de aumentar a audiência e atrair potenciais patrocinadores (...) A decisão de incluir um ou outro esporte vale apenas para aquela edição dos Jogos, não havendo necessidade de mantê-los na edição seguinte". Podemos, portanto, entender esta notícia como uma espécie de protótipo para a situação que se construiu posteriormente, sendo ela fonte historiográfica que nos permite reconstituir um momento histórico singular.

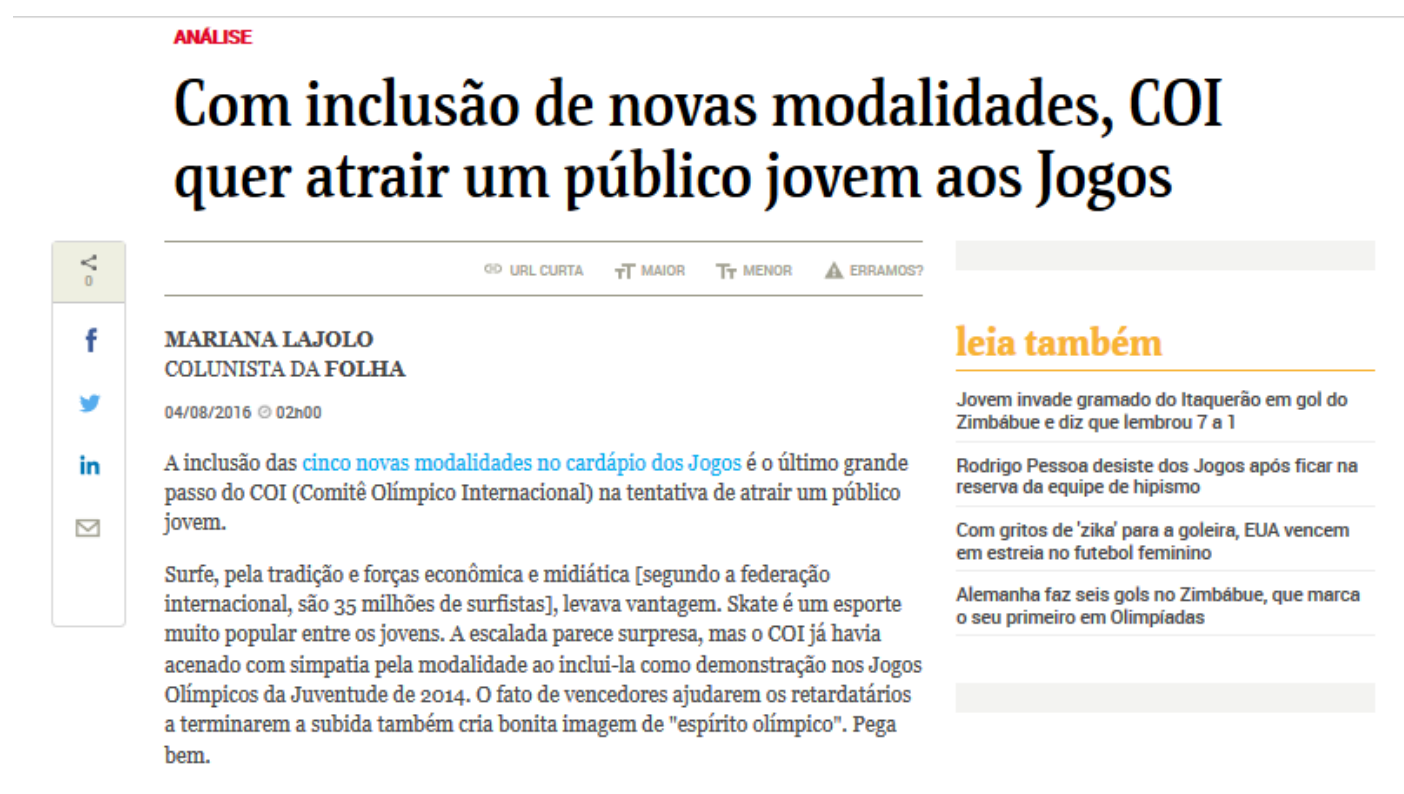

Na contramão da proposta de analisar as reportagens cronologicamente, estabeleceremos vínculos temáticos. A coluna, publicada na Folha de São Paulo, de autoria de Mariana Lajolo, mais do que apresentar um elemento factual, permite certa contextualização sobre o evento de inclusão de modalidades olímpicas. Mariana nos apresenta a todo tempo questionamentos a respeito da real necessidade de inclusão destes esportes enquanto olímpicos (Imagem 2). De forma a marcar a temporalidade e a importância histórica do momento relatado na notícia, Lajolo opta por um vocabulário simples, porém bastante dinâmico e explicativo, o que atrai a atenção do possível público leitor esperado para esta editoria.

Sustentada ainda no pilar de atração de um público jovem enquanto estratégia de marketing para renovação da audiência dos Jogos Olímpicos, a narrativa prossegue com uma breve explicação histórico-econômica-social acerca do porquê da inclusão de tais modalidades. No caso das duas analisadas por este artigo, sugere-se que a principal força motriz estaria na tradição e no amplo público adepto de ambas as atividades, o que, enquanto documento histórico, vem reforçar a ideia de que, mesmo sendo classificadas enquanto atividades

6 https://www1.folha.uol.com.br/esporte/olimpiada-no-rio/2016/08/1798748-com-inclusao-de-novas-modalidades-coi-quer-atrair-um-publico-jovem-aos-jogos.shtml acessado em 25 de março de 2020 
marginalizadas, skate e surfe se amparam na tradição para, cada vez mais, ganhar mais espaço entre os praticantes e, sobretudo, entre o público que não mais se restringe à parcela jovem da população ${ }^{7}$.

Porém, na contramão de construir um cenário ideal e de certa forma fantasioso, Mariana Lajolo parece sugerir, ainda que subliminarmente, que a inclusão de tais modalidades, muito mais do que um momento glorioso para a prática esportiva, se revela um excelente produto mercantilizado. Esta afirmação poderia ser comprovada no trecho em que afirma que

\begin{abstract}
A Olimpíada da Juventude foi um dos primeiros acenos do COI para tentar diminuir a faixa etária de seu público. O evento serve para chamar a atenção dos jovens, mostrar novos talentos e testar modalidades mais atraentes a eles. A entidade passou ainda a investir na comunicação, principalmente via redes sociais.
\end{abstract}

Além disso, surgem questionamentos por parte da colunista, típicos recursos utilizados neste gênero jornalístico, no qual avalia a real necessidade da inclusão destas duas atividades, skate e surfe, no rol de modalidades olímpicas. Para ela, existem dificuldades evidentes: a possibilidade de exclusão de modalidades olímpicas devido ao número expressivo de atletas, os quais a competição não comportaria (o que vimos que não foi consolidado) e o fato de o surfe carregar consigo a premissa da imprevisibilidade quanto a eventos climáticos, que modificam e tornam de certa maneira incerta a ocorrência da modalidade no habitat em que cotidianamente acontece.

Longe de responder às perguntas implícitas, a matéria segue com uma espécie de contextualização vaga, que apresenta ao leitor, leigo, informações básicas a respeito das cinco modalidades olímpicas, o número de atletas e os órgãos responsáveis por sua gerência, além de alguns nomes de atletas reconhecidos em cada uma delas. Apesar de carregado de informações e questionamentos, temos ainda neste momento um cenário construído que ainda possui lacunas quanto à sua apresentação. Apesar disso, as duas matérias funcionam como importantes fontes históricas que, mesmo levando em consideração a imprevisibilidade do banco de dados armazenado no ambiente virtual, servirão de fontes históricas que ajudarão a futuros pesquisadores reconstruir, com alguma legitimidade, o momento histórico precedente às Olimpíadas de 2020.

7 Mariana Lajolo analisa que “A inclusão das cinco novas modalidades no cardápio dos Jogos é o último grande passo do COI (Comitê Olímpico Internacional) na tentativa de atrair um público jovem. Surfe, pela tradição e forças econômica e midiática [segundo a federação internacional, são 35 milhões de surfistas], levava vantagem. Skate é um esporte muito popular entre os jovens."

8 LAJOLO, Mariana. Com inclusão de novas modalidades, COI quer atrair um público jovem aos Jogos. Folha de São Paulo, São Paulo, 03 de agosto de 2016. Análise. Disponível em: https://www1.folha.uol.com.br/esporte/olimpiada-no-rio/2016/08/ 1798748-com-inclusao-de-novas-modalidades-coi-quer-atrair-um-publico-jovem-aos-jogos.shtml acessado em 25 de março de 2020 . 
Imagem 03: Globo Esporte ${ }^{9}$ e Folha de São Paulo ${ }^{10}$

三 меми ge 0

\section{Jogos de Tóquio 2020 terão escalada, surfe, skate, caratê e beisebol/softbol}

Novas modalidades olímpicas são confirmadas durante Congresso do COI no Rio, Antes de votação, comitê organizador fez relatório sobre o estágio da preparação

Por cand Mota o Vioonto asds

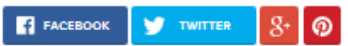

Surfe, skate, beisebolsoftbol, escalada e caratê farão parte do programa olímpico nos Jogos de Tóquio 2020. A inclusão dos cinco esportes foi confirmada por unanimidade nesta quarta-feira pelo Comitê Olimpico Internacional (COI), durante o congresso da entidade, realizado num hotel na Barra da Tijuca, no Rio de Janeiro. A lista de recomendações havia sido divulgada pelo comitê executivo em junho.

A inclusão dos cinco esportes faz parte do pacote de reformas iniciadas pelo presidente do COI, Thomas Bach, em dezembro de 2014. A ideia é que os anfitriöes dos Jogos tenham a chance de trazer ao ambiente olimpico esportes que sejam mais populares em seus paises, com intenção de aumentar a audiência e atrair potenciais patrocinadores. Porém, a decisão de incluir um ou outro esporte vale apenas para a edição da Olimpiada em questão, não havendo garantie de presença na edição seguinte.

De acordo com o Comitê Tóquio 2020, a inclusão dos novos esportes resultará no acréscimo de mais de 400 atletas em 18 disputas por medalhas nos Jogos Olimpicos. Quando o processo de inclusão de outras modalidades foi aberto, mais de 200 se inscreveram.

\section{COI aprova entrada de surfe, caratê e skate para Olimpíada de Tóquio-2020}

\begin{tabular}{|c|c|c|}
\hline$\infty$ URL CUATA & TT MAIOR TT MENOR A ERRAMOS? & \\
\hline \multicolumn{3}{|l|}{ ADRIANA KÜCHLER } \\
\hline \multicolumn{3}{|l|}{ GUILHERME ZOCCHIO } \\
\hline \multirow{2}{*}{\multicolumn{3}{|c|}{$\begin{array}{l}\text { DE SÃO PAULO } \\
\text { CAMILA MATTOSO }\end{array}$}} \\
\hline \multirow{2}{*}{\multicolumn{2}{|c|}{ ENVIADA ESPECLAL AO RIO }} & \\
\hline & & $\begin{array}{l}\text { Comitê Olimpico Internacional tenta colocar mais } \\
\text { mulheres em altos cargos }\end{array}$ \\
\hline \multicolumn{2}{|l|}{ 03/08/2016 ○ 16n43 $\mathbf{\Delta}$ Erramoa: o texto foi alterado } & $\begin{array}{l}\text { COl admite antecipar recursos para comitê } \\
\text { organizador da Rio-2016 }\end{array}$ \\
\hline \multicolumn{2}{|c|}{$\begin{array}{l}\text { O COI (Comitê Olímpico Internacional) aprovou a inclusão de cinco modalidades } \\
\text { para a próxima edição de Jogos Olímpicos. Surfe, beisebol/softbol, caratê, skate e } \\
\text { escalada farão parte da programação de Tóquio-2020. }\end{array}$} & $\begin{array}{l}\text { Campanha de candidatura do Rio para os Jogos } \\
\text { teve pedidos de 'mimos' }\end{array}$ \\
\hline \multicolumn{2}{|c|}{$\begin{array}{l}\text { A decisão foi tomada por membros do comitê em seu congresso realizado em um } \\
\text { hotel na Barra da Tijuca, no Rio. }\end{array}$} & $\begin{array}{l}\text { Apesar da pouca estrutura skate sobrevive há } \\
\text { décadas na ruas de SP }\end{array}$ \\
\hline \multicolumn{3}{|c|}{$\begin{array}{l}\text { O conselho executivo da entidade aprovou em junho a proposta feita pelo comitê } \\
\text { organizador dos Jogos de } 2020 \text { de adicionar esses cinco esportes. }\end{array}$} \\
\hline
\end{tabular}

A escolha pela análise comparativa das matérias publicadas pelo portal Globo Esporte e Folha de São Paulo está ancorada no fato de terem sido encontradas similaridades diversas nos dois textos. Publicadas no mesmo dia, ambas apresentam o elemento factual da aprovação de

9 http://globoesporte.globo.com/olimpiadas/noticia/2016/08/jogos-de-toquio-2020-terao-escalada-surfe-skate-carate-e-beisebolsoftbol.html acessado em 25 de março de 2020

10 https://www1.folha.uol.com.br/esporte/olimpiada-no-rio/2016/08/1798748-com-inclusao-de-novas-modalidades-coi-quer-atrair-um-publico-jovem-aos-jogos.shtml acessado em 25 de março de 2020 
ambas as modalidades aqui estudadas entre as disputas olímpicas da edição de 2020, além das outras três que não são nosso objeto de estudo. Sustentando que a decisão não foi tomada de maneira imediata, mas sim como resultado de uma série de ponderações dos possíveis impactos de suas inclusões, os jornalistas apresentaram o fato como essenciais e extremamente positivos. Apontaram, acima de tudo, os benefícios da inclusão do skate e do surfe como modalidades olímpicas, projetando um cenário de amplos benefícios que partiriam desta decisão.

A diferença de tratamento em relação às demais matérias está na ampliação de fontes, que possibilitou aos jornalistas desenvolverem o tema de forma que se tornasse mais claro ao público leitor dos dois portais noticiosos. No que tange à primeira matéria, publicada em 03 de agosto de 2016 pelo portal Globo Esporte, pudemos encontrar mais uma vez a tentativa de construção do cenário resultante da inclusão das cinco modalidades. Frases como "a inclusão dos novos esportes resultará no acréscimo de mais de 400 atletas em 18 disputas por medalhas nos Jogos Olímpicos. Quando o processo de inclusão de outras modalidades foi aberto, mais de 200 se inscreveram" reconstroem, ainda que de forma subliminar, que esta decisão foi acertada, mas também marcada por um cenário de disputas acirradas que culminou na decisão pela inserção das cinco modalidades: escalada, beisebol, surfe, skate e caratê.

A construção discursiva perpassa também pela apresentação do evento como elemento de marketing e, assim como a matéria da Folha, a matéria do portal Globo Esporte também destacou a inclusão das modalidades aqui tomadas como objetos do artigo como força atrativa para um público cada vez mais jovem. Segundo a matéria "Temos a histórica oportunidade em Tóquio de ter a chance de novos eventos e de fazermos os Jogos mais inovadores da história. Acreditamos que esses esportes trarão novos elementos aos Jogos, como atrair maior atenção do público jovem pelo mundo". As assertivas, validadas por presidente do comitê organizador da Olimpíada de 2020, Yoshiro Mori, e o seu diretor-executivo, Toshiro Muto, ressaltam a relevância da decisão. Porém, tais declarações colocam em xeque a questão mercadológica do evento ao ressaltar a necessidade de atração de um público jovem que se tornará potencial consumidor nas mais variadas áreas: ingressos, hotéis, lembrancinhas, passagens aéreas ou simplesmente sendo convertido em audiência, acompanhando o evento nos veículos de comunicação e que, de certa forma, podem contribuir para aumentar o número de praticantes das modalidades inseridas no rol Olímpico nos anos posteriores ao evento.

Outras fontes também foram ouvidas para destacar a importância da inclusão das duas modalidades aqui estudadas no rol olímpico. Os representantes das entidades organizadoras de ambas as modalidades destacam a importância do status "olímpico" para a projeção ainda maior no cenário esportivo, tendo até mesmo a possibilidade de atrair novos adeptos. Ao assumir o status de "olímpicos", tais esportes atingem um grau de importância de dimensões inimagináveis. Isto pode ser justificada pela imagem que o esporte olímpico assume na mentalidade coletiva: muito mais do que um evento esportivo, tornar-se olímpico significaria transpor uma barreira simbólica. Considerada o maior evento em dimensões globais que reúnem diversas modalidades, as Olimpíadas são responsáveis por projetar seus campeões a status de heróis, mitos e modelos a serem seguidos. Assim sendo, a transformação em esporte olímpico traz consigo elementos que, muito mais do que um mero status, ajudam a consolidar a importância destas práticas no mundo esportivo.

Construindo um cenário positivo, a matéria traz relatos que, de certa forma, fazem-nos esquecer do passado marginalizado de tais indivíduos no cenário nacional e internacional. Para validar tal afirmação, nos apoiamos na declaração otimista de Gabriel Medina, que procura 
construir discursivamente, a importância da decisão do COI. A fala de Medina, que compõe a matéria, ilustra os impactos da decisão do COI para a modalidade. Isso revela que, muito mais do que um mero evento esportivo, as Olimpíadas ainda carregam simbolismos importante, que advêm da época de sua reformulação, realizada pelo Barão de Cobertin em 1890: o status olímpico, que oferece a glória dos heróis àqueles que se sagrarem campeões por seus méritos, pela exaltação de sua dedicação.

Recebi algumas mensagens de pessoas que gostam do surfe. Todos os surfistas estão felizes por fazer parte disso. Estou amarradão, né? Agora, vamos para Tóquio representar o Brasil. É um sonho fazer parte das Olimpíadas. Vai ser demais! O surfe tem crescido muito. É um esporte jovem e tem tudo a ver com as Olimpíadas. Na real, já era até para ter tido. Demorou, o Fernando mesmo tem lutado há mais de 20 anos, e chegou o dia. O surfe é um esporte maneiro, é legal de assistir, todo mundo gosta. ${ }^{11}$

Já na segunda matéria, publicada na mesma data pela Folha de São Paulo, o retrato foi, de certa maneira, semelhante. Apesar de repetir, no final da matéria, o trecho de elementos informativos sobre as modalidades, seus órgãos gestores e potenciais atletas representantes, foi feito um aprofundamento do tema em diversos aspectos. Apresentando uma série de fotos que exaltam os possíveis representantes brasileiros nas modalidades, os jornalistas desta matéria optam por fundamentar o cenário otimista desta inclusão no rol de modalidades olímpicas nas falas de representantes de confederações e de atletas.

No caso do surfe, foi creditada a Adriano de Souza, o Mineirinho, campeão do surfe mundial à época da publicação, a informação de que "ser olímpico" representaria um importante passo para o reconhecimento ainda maior da modalidade, que já estava em franco crescimento. "Acredito que, com o esporte entrando no ciclo olímpico, poderemos ver uma organização melhor entre confederações e federações. Se fizerem tudo certinho, seremos uma superpotência do surfe mundialmente".

Já no que tange ao caso do skate, a matéria não aprofunda, sequer traz um depoimento de um dos potenciais representantes brasileiros ou até mesmo do órgão gestor, tal como fez com as outras quatro modalidades. Apenas é informado ao leitor de que a competição olímpica para tal esporte será nas modalidades park e street, ainda com ausência explicativa. O que isso pode significar? Menor importância da modalidade? Menor afinidade com o tratamento dela? Ausência de respostas do possível contato feito com representantes da modalidade?

Para finalizar, a matéria nos apresenta, tal como as demais analisadas, o cenário mercantilista que marca o evento esportivo. Segundo fontes constadas na matéria, o aporte financeiro possibilitado por tal inclusão no rol olímpico permitiria com que as modalidades pudessem investir em desenvolvimento e, consequentemente, no maior grau de habilidade dos atletas envolvidos. Porém, com a afirmação de que "Com esses acréscimos, a Olimpíada de 2020 deverá ter mais 18 eventos, considerando as categorias dessas modalidades.", fica claro o real motivo pelo qual estas atividades puderam fazer parte das disputas olímpicas: necessidade de ampliação nos investimentos financeiros, uma vez que, fugindo de suas raízes, os Jogos

11 MOTA, Cauê; SEDA, Vicente. Jogos de Tóquio 2020 terão escalada, surfe, skate, caratê e beisebol/softbol. Globo Esporte, São Paulo. 03 de agosto de 2016. Olimpíadas. Disponível em: http://globoesporte.globo.com/olimpiadas/noticia/2016/08/ jogos-de-toquio-2020-terao-escalada-surfe-skate-carate-e-beisebolsoftbol.html 
Olímpicos modernos representariam um relevante e essencial produto mercadológico.

Longe de considerar o conteúdo jornalístico como algo neutro ou imparcial, tal como sugerem algumas linhas teóricas do campo jornalístico, o que nos importa aqui é entender a forma com que o evento histórico estudado foi apresentado sob a ótica de dois dos mais consolidados conglomerados de mídia brasileiros (KOVACK; ROSENSTIEL, 2004). O tratamento do tema pelos jornalistas é, de certa maneira, bastante parcial, em uma tentativa de reconstruir o cenário do evento histórico por eles noticiado. Nas notícias preliminares da inclusão das cinco novas modalidades pudemos perceber uma certa superficialidade no tratamento do tema, tal como geralmente acontece nas matérias jornalísticas pela dinamicidade da rotina de redações e, principalmente, do suporte utilizado para disseminação da matéria, a internet, marcada por instantaneidade e efemeridade dos conteúdos disponibilizados nela. No momento em que procuramos estabelecer uma relação comparativa do tratamento do tema "inclusão no rol de modalidades olímpicas" é que as narrativas sofrem contraste significativo, o que revela explicitamente o perfil editorial dos veículos midiáticos tomados como objeto desta pesquisa.

\section{Considerações finais}

Tomado como uma das ferramentas essenciais para reconstrução de um evento histórico, os jornais, assim como outras fontes históricas documentais, viram as tecnologias da informação e comunicação ampliarem o escopo de objetos tomados como pesquisa por diversos pesquisadores das mais variadas áreas do conhecimento. Através da digitalização dos materiais e, até mesmo, a possibilidade de produzi-los e socializa-los através das redes, pudemos assistir a uma nova maneira de reconstrução do passado.

A escolha pelo anúncio da inclusão das cinco modalidades olímpicas está sustentada no fato de ser um momento histórico singular, que demarca o pontapé para os desenvolvimentos posteriores. Na tentativa de reconstruir este evento singular e verificar o modo com que veículos distintos o retrataram, pudemos perceber que, àquele momento, os jornalistas apresentavam aos leitores um cenário incerto, sem muitas informações consistentes ou esclarecedoras. $\mathrm{O}$ que parece é que, mesmo utilizando como base as declarações de atletas reconhecidos em suas modalidades e até mesmo dirigentes, o que se configurava neste momento histórico era um ambiente de incertezas quanto à forma pela qual as cinco atividades esportivas seriam estruturadas para compor o quadro de modalidades olímpicas.

Ao intentar reconstruir este evento histórico, nos deparamos com um cenário bastante peculiar. Através das narrativas jornalísticas, o que se observou foi que as construções discursivas se transformaram, se comparados aos estigmas impostos aos praticantes ainda na gênese das duas práticas em solo nacional. No decorrer das décadas, a influência de diversos eventos históricos possibilitou a mudança do imaginário social partilhado sobre estes grupos. De marginalizados e "outsiders", reconhecidos como subversivos à ordem urbana instituída e marcada pelo contexto ditatorial brasileiro, os praticantes das duas modalidades puderam experimentar um momento de reconhecimento que, diferente do que possa parecer, foi resultado de mudanças nas concepções construídas sobre eles no decorrer dos períodos históricos, em muito influenciados pelas revoluções políticas, econômicas, sociais e culturais 
que se desenrolaram no mundo.

Mesmo após inúmeras transformações nas duas modalidades, sendo estas institucionalizadas e com regras próprias, o que se pode ainda hoje observar é a relação de ambas as atividades com a parcela juvenil da população. Este fato pôde se fazer observável quando constatamos a "relação com a juventude" como elemento central de estratégia de marketing para renovação da audiência dos Jogos Olímpicos. Assim, tal como desenvolvido pela terceira geração da Escola de Annales, o que pudemos constatar é que os jornais, sejam eles em que plataforma se encontrem, continuam a ser objeto de estudo por parte dos historiadores e demais pesquisadores que se relacionam à questões sociais, uma vez que serve como elemento de legitimidade para tentar reconstruir um determinado período histórico.

\section{Referências Bibliográficas}

BACZKO, Bronislaw. Les imaginaires sociaux. Mémoire et espoirs colletifs. Paris: Payot, 1984

BARBANTI, Valdir. O que é esporte? Revista Brasileira de Atividade Física \& Saúde, v. 11, n. 1, p. 54-58, 2006.

BARBOSA,Marialva. Jornalismo no Brasil: dois séculos de história. In: Jorge Pedro Sousa. (Org.). Jornalismo: História, Teoria e Metodologia da Pesquisa..1ed.Porto: Universidade Fernando Pessoa, 2008, v. 1, p. $129-154$

BERGER, Peter L.; LUCKMANN, Thomas. A construção social da realidade: tratado de sociologia do conhecimento. Petrópolis: Vozes, 2014

BRANDÃO, Leonardo. Para além do esporte: uma história do skate no Brasil. Blumenau: Edifurb, 2014.

CALLOIS, Roger. Os jogos e os homens: a máscara e a vertigem. Lisboa: Cotovia, v. 15, 1990.

CARLOS, Ana Fani A.; SOUZA, Marcelo JL; SPOSITO, Maria Encarnação Beltrão. A produção do espaço urbano: agentes e processos, escalas e desafios. São Paulo. Editora Contexto, 2019.

CERTEAU, Michel de. A invenção do cotidiano 2. Morar, Cozinhar. Petrópolis: Vozes, 1996

COUTO et al. Juventude e o uso do espaço urbano para a prática do lazer. In. BRANDÃO, L. (org). Esporte, Lazer e Desenvolvimento Regional. Blumenau: Edifurb, 2019. p. 33-48.

DAMATTA, Roberto. A casa e a rua. Rio de janeiro: Rocco, v. 5, 1997.

DIAS, Cleber Augusto Gonçalves. Urbanidades da natureza: o montanhismo, o surfe e as novas configurações do esporte no Rio de Janeiro. Rio de Janeiro: Apicuri, 2008. 
DUNNING, Eric; ELIAS, Norbert. A busca da excitação. Lisboa: Difel, 1992.

ECO, Umberto. Obra aberta: forma e indeterminação nas poéticas contemporâneas. São Paulo: Editora Perspectiva SA, 2016.

FEVBRE, Lucien. Combates pela história. Trad. Leonor Martinho Simões e Gisela Moniz. Lisboa: Editorial Presença, 1989

HOBSBAWM, Eric. Era dos extremos: o breve século XX. São Paulo: Editora Companhia das Letras, 1995. . A era das revoluções. Rio de Janeiro: Paz e Terra, 2006.

HUIZINGA, Johan. Homo ludens: o jogo como elemento da cultura. São Paulo: Editora da Universidade de S. Paulo, Editora Perspectiva, 1971.

JACOBS, Jane. Morte e vida de grandes cidades. São Paulo: Martins Fontes, 2014

KOVACK, Bill, and Tom ROSENSTIEL. "O que os jornalistas devem saber e o público exigir." São Paulo: Geração Editorial, 2004.

MAGNANI, José Guilherme Cantor. "Rua, Símbolo e Suporte da Experiência Urbana”. 1993. Disponível em http: //www.Aguaforte.com//antropologia

MORGADO, Eliane Maria. Catálogo de jornais, revistas e boletins de Mato Grosso 1847-1985. Cuiabá: EdUFMT, 2011

PESAVENTO, Sandra Jatahy. História \& história cultural. Belo Horizonte: Autêntica, 2012.

SANTOS, Milton. A natureza do espaço: técnica e tempo, razão e emoção. São Paulo: Edusp, 2006.

SERPA, Angelo. O espaço público na cidade contemporânea. São Paulo: Editora Contexto, 2018.

TUAN, Vi-fu. Espaço e lugar: A perspectiva da experiência. São Paulo: DIFEL, 1983)

TUBINO, Manoel J. G. O que é esporte. São Paulo: Brasiliense, 1994.

RECEBIDO EM: $18 / 02 / 2020$

APROVADO EM: 23/04/2020 